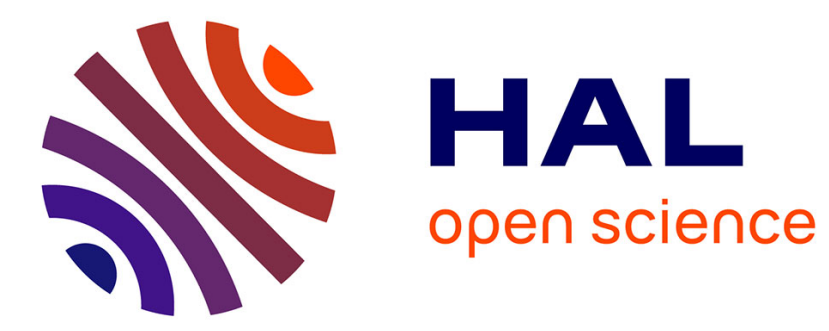

\title{
Group-to-Individual Problem-Solving Transfer
}

\author{
Patrick R. Laughlin, Harold R. Carey, Norbert L. Kerr
}

\section{To cite this version:}

Patrick R. Laughlin, Harold R. Carey, Norbert L. Kerr. Group-to-Individual Problem-Solving Transfer. Group Processes and Intergroup Relations, 2008, 11 (3), pp.319-330. 10.1177/1368430208090645 . hal-00571690

\section{HAL Id: hal-00571690 https://hal.science/hal-00571690}

Submitted on 1 Mar 2011

HAL is a multi-disciplinary open access archive for the deposit and dissemination of scientific research documents, whether they are published or not. The documents may come from teaching and research institutions in France or abroad, or from public or private research centers.
L'archive ouverte pluridisciplinaire HAL, est destinée au dépôt et à la diffusion de documents scientifiques de niveau recherche, publiés ou non, émanant des établissements d'enseignement et de recherche français ou étrangers, des laboratoires publics ou privés. 


\title{
Group-to-Individual Problem-Solving Transfer
}

\author{
Patrick R. Laughlin \\ University of Illinois at Urbana-Champaign \\ Harold R. Carey \\ COLSA International, Huntsville, Alabama
}

\author{
Norbert L. Kerr \\ Michigan State University
}

\begin{abstract}
Many scientific, educational, business, military, and political groups assume that people who solve problems in groups and teams will solve subsequent problems better as individuals than people without previous group problem-solving experience. In order to assess such group-to-individual transfer, sets of three people solved four letters-to-numbers decoding problems as groups (G) or individuals (I) in five conditions: GGGG, GGGI, GGII, GIII, or IIII. Results supported four hypotheses: (a) groups performed better than individuals, (b) positive group-to-individual transfer occurred, (c) one group experience was sufficient for transfer, (d) transfer was at the level of group performance (complete) on problems 2 and 3 but incomplete on problem 4, due to exceptional performance in the GGGG condition.
\end{abstract}

KEYWORDS group-to-individual transfer, letters-to-numbers problems

MANy scientific, educational, business, military, and political groups assume that people who solve problems in groups solve subsequent problems as individuals better than individuals who have not had this previous experience in group problem solving. This is the fundamental issue of groupto-individual transfer. The transfer problem may be the same as the training problem, defining specific group-to-individual transfer, or a new problem of the same general class, defining general group-to-individual transfer.

One approach to assess either specific or general group-to-individual transfer uses a three-stage IGI versus III design. In the IGI experimental condition participants solve problems as individuals (I), then as groups $(G)$, and then as individuals (I). In the III control condition the participants solve the same problems three times as individuals. Group-to-individual transfer is demonstrated by better third stage performance for individuals in the IGI condition than the III condition. Although with random assignment to conditions only a GI versus II design is necessary to assess transfer, an IGI versus III design also

\footnotetext{
$\overline{\text { Author's note }}$

Address correspondence to Patrick R. Laughlin, Department of Psychology, University of Illinois, 603 E. Daniel St, Champaign, IL 61820, USA

[email: plaughli@uiuc.edu]
} 
allows model-fitting analyses of the social combination processes by which the groups map known distributions of correct and incorrect members to a correct or incorrect group response (Kerr, Stasser, \& Davis, 1979).

Four reported studies have used this IGI versus III design. Laughlin and Adamopoulos (1980) demonstrated specific transfer with this design when the same 30 verbal analogies problems were administered three times, and Laughlin and Ellis (1986) demonstrated specific transfer when the same 10 algebra, geometry, and probability problems were administered three times. Stasson, Kameda, Parks, Zimmerman, and Davis (1991) administered the same five algebra, geometry, and probability problems for the first two administrations, and then new problems that could be solved by the same general principle or equation on the third administration. The IGI individuals performed better on the third administration than the III individuals, demonstrating general group-to-individual transfer. Olivera and Straus (2004) used an III versus IGI versus IVI (participants watched a videotape $(\mathrm{V})$ of a group solving the problems) design with brainteasers such as hidden word problems. The IGI individuals who had been in groups solved the problems better on the third administration than the III individuals who had not been in groups. Watching a videotape of a group solving the problems did not improve subsequent individual performance, indicating that actual participation in group problem solving was necessary for transfer to occur.

A truth-wins model provided the best fit in both the Laughlin and Ellis (1986) and Stasson et al. (1991) studies, indicating that one correct member was necessary and sufficient for a correct group response on the highly demonstrable mathematical problems. A truth-supported wins model provided the best fit in the Laughlin and Adamopolous (1980) study, indicating that two correct group members were necessary and sufficient for a correct group response on the less demonstrable verbal analogy problems. This indicates that the incorrect group members in all three studies were able to learn from the correct member(s), providing a basis for subsequent transfer to their individual problem solving.

\section{Four issues in group-to-individual problem-solving transfer}

All four of these studies used a single training session and a single transfer session. As a result all four studies assessed only two issues: (a) group versus individual training performance, (b) group-to-individual transfer. If there is more than one training session, there are two further issues: (c) sufficiency and (d) completeness. Sufficiency is the issue whether one training session is sufficient for group-to-individual transfer. Completeness is the issue whether groupto-individual transfer is complete, i.e. whether individual performance on the transfer problems is at the level of performance by comparably experienced groups on the same problems.

Our experiment assessed these four issues of group-to-individual problem-solving transfer on letters-to-numbers problems. The ten letters A, B, C, D, E, F, G, H, I, J are randomly coded to the 10 digits $0,1,2,3,4,5,6,7,8,9$, and the objective is to identify the complete coding in as few trials as possible. On each trial (up to a maximum of 10) the participant(s) first generates an arithmetic expression in the letters $\mathrm{A}, \mathrm{B}, \ldots, \mathrm{J}$ with plus and/or minus signs (operators) (e.g. $\mathrm{C}+\mathrm{G}$ ) on a computer terminal. The program then computes and displays the value of the expression (e.g. $\mathrm{C}+\mathrm{G}=\mathrm{ED}$ ). The participant then enters a coding for the number $0,1, \ldots, 9$ corresponding to a letter for as many of the 10 letters as desired (e.g. $\mathrm{E}=1$ ). The computer then indicates whether the hypotheses are correct or incorrect. Hence there are four stages on each trial: (a) formulating and entering of an expression, (b) reasoning from the computer-generated value of that expression, (c) assignment of a number to one or more of the remaining unidentified letters, $(\mathrm{d})$ reasoning from the provided feedback that the assignment of numbers to letters is correct or incorrect.

We expanded the traditional GI versus II design to include three GGGI, GGII, and GIII conditions in which the participants solved three, two, or one problem as a group before solving one, two, or three problems as individuals, and expanded the traditional II condition to an IIII control condition in which the participants 
solved four successive problems as individuals. Further expanding the traditional IG versus II design, we included a GGGG group control condition in which the participants solved four successive problems as a group.

Contrasts of the group and individual conditions within each of the four problems address four issues of group-to-individual transfer. First, do groups perform better than individuals? Second, does positive group-to-individual transfer occur? Third, is a single group experience sufficient for a full group-to-individual transfer effect, or is extended group experience essential? Fourth, is group-to-individual transfer complete, i.e. at the level of group performance, or does limited prior group experience produce only limited individual improvement? Figure 1 summarizes 16 contrasts that address these four issues. The bottom part of Figure 1 places a check mark under the particular contrasts and weights that test Hypotheses 1, 2, 3, and 4.

\section{Hypothesis 1. Groups will perform better than individuals}

Better performance for groups than individuals is a likely (if not necessary) prerequisite for positive group-to-individual transfer. As indicated in Contrast 1 of Figure 1, Hypothesis 1 is tested on Problem 1 by comparison of (GGGG, GGGI, GGII, GIII) versus IIII, with respective weights of -1 for each of GGGG, GGGI, GGII, and GIII, and 4 for IIII. Similarly, Hypothesis 1 is tested on Problem 2 by comparison of the three conditions that solve the first two problems as a group (GGGG, GGGI GGII) versus the IIII condition that solves the first two problems as an individual (Contrast 3), with respective weights of -1 for each of GGGG, GGGI, and GGII, 0 for GIII, and 3 for IIII. Hypothesis 1 is tested on Problem 3 by comparison of (GGGG, GGGI) versus III (Contrast 8); and on Problem 4 by comparison of GGGG and IIII (Contrast 12).

\section{Hypothesis 2. Positive group-to-individual transfer will occur}

Letters-to-numbers problems entail demonstrably effective approaches, strategies, and generalizations that may be learned during group problem solving, either by one group member from another or as emergent insights that none of the group members would have realized alone (see Laughlin, Bonner, \& Miner, 2002; Laughlin, Zander, Knievel, \& Tan, 2003). These approaches, strategies, and generalizations should be transferable to subsequent individual problem solving. Hence we expected positive

\begin{tabular}{|c|c|c|c|c|c|c|c|c|c|c|c|c|c|c|c|c|}
\hline & \multicolumn{16}{|c|}{ Problem } \\
\hline & 1 & & 2 & & & & 3 & & & & & & 4 & & & \\
\hline Contrast & 1 & 2 & 3 & 4 & 5 & 6 & 7 & 8 & 9 & 10 & 11 & 12 & 13 & 14 & 15 & 16 \\
\hline
\end{tabular}

\begin{tabular}{|l|r|rrr|rrrrrrrrrrrrr|}
\hline GGGG & -1 & -1 & -1 & 0 & 0 & 0 & -1 & -1 & 0 & 0 & 0 & -1 & 0 & 0 & 0 & -3 \\
\hline GGGI & -1 & -1 & -1 & 0 & 0 & 0 & -1 & -1 & 0 & 0 & 0 & 0 & 0 & -1 & -1 & 1 \\
\hline GGII & -1 & -1 & -1 & 0 & 0 & -1 & 1 & 0 & -1 & -1 & 0 & 0 & -1 & 0 & 0 & 1 \\
\hline GIII & -1 & 3 & 0 & -1 & -1 & 1 & 1 & 0 & 0 & 0 & -1 & 0 & 1 & 1 & 0 & 1 \\
\hline IIII & 4 & 0 & 3 & 1 & 1 & 0 & 0 & 2 & 1 & 1 & 1 & 1 & 0 & 0 & 1 & 0 \\
\hline
\end{tabular}

Contrast relevant to hypothesis? ( $\sqrt{ }$ means yes $)$

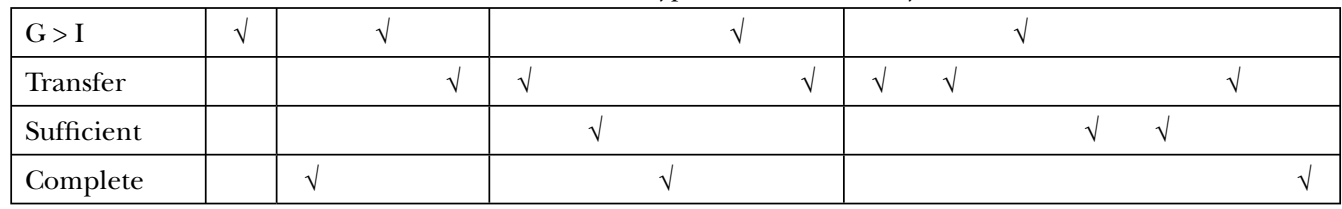

Figure 1. Summary of hypotheses and contrasts. 
group-to-individual transfer, in which individuals with previous group experience perform better than individuals without previous group experience. As indicated in Figure 1, Hypothesis 2 is tested on Problem 2 by comparison of GIII and IIII (Contrast 4); on Problem 3 by comparisons of (a) GIII and IIII (Contrast 5), and (b) GGII and IIII (Contrast 9); and on Problem 4 by comparisons of (a) GGII and IIII (Contrast 10), (b) GIII and IIII (Contrast 11), and (c) GGGI and IIII (Contrast 15).

\section{Hypothesis 3. One previous group experience is sufficient for positive group-to-individual transfer to occur}

Because previous groups have been demonstrated to use effective approaches, strategies, and generalizations on letters-to-numbers problems (Laughlin et al., 2002, 2003; Laughlin, Hatch, Silver, \& Boh, 2006) we hypothesized that solving one problem as a group would be sufficient for the members to learn such effective approaches, strategies, and generalizations that would transfer to subsequent individual problem solving. Thus, the GIII individuals who have solved one previous problem as a group should perform as well on Problem 3 as the GGII individuals who have solved two previous problems as a group (Contrast 6). Similarly, the GIII individuals who have solved one previous problem as a group should perform as well on Problem 4 as the GGII individuals who have solved two previous problems as a group (Contrast 13), and the GIII individuals who have solved one previous problem as a group should perform as well on Problem 4 as the GGGI individuals who have solved three previous problems as a group (Contrast 14). Significant differences for these contrasts would indicate that more than one group experience is necessary for positive group-to-individual transfer and help identify just how much prior experience is required.

\section{Hypothesis 4. Group-to-individual transfer will be complete}

Hypotheses 2 and 3 assess the occurrence and sufficiency of group-to-individual transfer by a comparison of individuals who have had previous group problem-solving experience with individuals who have not had previous group problem-solving experience. Hypothesis 4 is the stronger prediction that strategies and generalizations learned while solving a single problem as a group should be fully understood by the group members and consequently result in subsequent individual problem-solving at the level of group problem-solving on the same problem. As indicated in Figure 1, Hypothesis 4 is tested on Problem 2 by comparison of (GGGG, GGGI, GGII) and GIII (Contrast 2); on Problem 3 by comparison of (GGGG, GGGI) and (GGII, GIII) (Contrast 7); and on Problem 4 by comparison of GGGG and (GGGI, GGII, GIII) (Contrast 16).

\section{Method}

\section{Participants and design}

The participants were 525 college students, 300 at Michigan State University and 225 at the University of Illinois at Urbana-Champaign. They received course credit for participation. There were five experimental conditions defined by group (G) problem solving or individual (I) problem solving for four successive problems: GGGG, GGGI, GGII, GIII, and IIII. The participants in the GGGG condition solved four successive problems as a three-person group. The participants in the GGGI condition solved three problems as a group and each person then solved one problem as an individual, the participants in the GGII condition solved two problems as a group and two problems as individuals, and the participants in the GIII condition solved one problem as a group and three problems as individuals. There were 20 replications of each of the five conditions at Michigan State University and 15 replications at the University of Illinois at Urbana-Champaign. The computer program generated a new random coding of the 10 letters to the 10 numbers for each problem for each group or individual.

\section{Procedure}

After signing informed consent forms, the participants were randomly assigned in sets of three 
to experimental conditions. In the GGGG, GGGI, GGII, and GIIII conditions three participants were seated at one computer and in the IIII condition the participants were seated at separate computers. The group or individuals then read the Instructions as given in Figure 2, and began the first problem, as illustrated in Figure 3. In the GGGG and IIII conditions the group or individuals solved four successive problems at the same terminal. In the GGGI, GGII, and GIII transfer conditions the three persons went to separate computers for individual problem solving after they had completed three, two, or one group problems, respectively. The groups were instructed to solve the problems cooperatively, reaching agreement on each expression and assignment of the numbers to letters on each trial. After the fourth problem was completed the experimenter gave the participants a written debriefing with a reference for further reading, answered any questions, and thanked them for their participation.

\section{Results}

\section{Trials to solution}

In Condition GIII the three persons who had previously been in a group on Problem 1 solved Problems 2, 3, and 4 as individuals. Similarly, in Condition GGII the three persons who had previously been in a group on Problems 1 and 2 solved Problems 3 and 4 as individuals, and in Condition GGGI the three persons who had previously been in a group on Problems 1, 2, and 3 solved Problem 4 as individuals. Thus, the number of trials to solution for these individuals may not have been independent. In order to test for nonindependence we computed the intraclass correlations on each of Problems 2, 3 , and 4, as recommended by Kenny, Kashy,

\section{Instructions for Letters-to-Numbers Game}

This is a very challenging game to test your cleverness.

The letters A B C D E F G H I J have been secretly assigned to the digits 0123456789 in a random way.

Your job is to figure out the digit that is assigned to each letter. For example, $\mathrm{A}=3, \mathrm{~B}=4, \mathrm{C}=7$, etc. There are no repeated assignments, so if $\mathrm{A}=3$, then $\mathrm{B}$ cannot be 3 .

Note: If $\mathrm{A}=1$ and $\mathrm{B}=3$, then $\mathrm{AB}=13$. Here $\mathrm{AB}$ does NOT mean $\mathrm{A}$ times $\mathrm{B}$.

Also note that the number you are seeking is 0 (zero), not 10 (ten).

A 'Trial' consists of these 4 steps:

1. You enter an expression consisting only of letters and + and -. For Example, A+A+BD-C

2. The computer shows you the value of that expression, using the coded letters. For example, BE

3. You enter a guess for the assignment of any or all letters, without repeating any number guesses.

4. The computer shows you which of your guesses are correct in green or incorrect in red.

Your objective is to figure out all 10 assignments of letters to numbers in as few 'Trials' as possible. You can have up to 10 Trials for each game.

Your only score for each game is how few Trials you use to guess the assignments of all letters to numbers.

You can use scratch paper or a calculator if you like. There is plenty of time.

You will play several games, but some might be in another Session on this computer, or on another computer.

Read these instructions again to be sure that you understand them perfectly.

Then type your name or your Group's name in this yellow box, then press "Enter" to play the game:

Figure 2. Instructions for letters-to-numbers problems. 


\begin{tabular}{|c|c|c|c|c|c|c|c|c|c|c|c|c|}
\hline \multirow[b]{2}{*}{ Trial } & \multirow[b]{2}{*}{ Expression } & \multirow[b]{2}{*}{ Value } & \multicolumn{10}{|c|}{ Guess } \\
\hline & & & A & B & C & D & $\mathrm{E}$ & $\mathrm{F}$ & G & $\mathrm{H}$ & I & $\mathrm{J}$ \\
\hline 1 & $\mathrm{C}+\mathrm{G}$ & $\mathrm{ED}$ & & & 7 & 3 & 1 & & 8 & & & \\
\hline 2 & $\mathrm{E}+\mathrm{E}$ & D & & & & 2 & 1 & 3 & 0 & 4 & 5 & 6 \\
\hline 3 & $\mathrm{D}+\mathrm{DDD}+\mathrm{EDE}$ & AGB & 3 & 5 & & 2 & 1 & 9 & 4 & 6 & 8 & 7 \\
\hline 4 & $\mathrm{EDA}+\mathrm{BBB}$ & FHC & 3 & 5 & 8 & 2 & 1 & 6 & 4 & 7 & 7 & 0 \\
\hline 5 & $\mathrm{E}+\mathrm{C}$ & $\mathrm{J}$ & 3 & 5 & 8 & 2 & 1 & 6 & 4 & 7 & 0 & 9 \\
\hline 6 & & & & & & & & & & & & \\
\hline 7 & & & & & & & & & & & & \\
\hline 8 & & & & & & & & & & & & \\
\hline 9 & & & & & & & & & & & & \\
\hline 10 & & & & & & & & & & & & \\
\hline
\end{tabular}

Figure 3. Illustrative computer screen during problem solution.

and Bolger (1998) and Kenny, Mannetti, Pierro, Livi, and Kashy (2002). These intraclass correlations were .38 for Problem 2, .33 for Problem 3, and .31 on Problem 4. According to these authors, an intraclass correlation of .10 indicates nonindependence, and 'If there is nonindependence, then group not person must be used as the unit of analysis' (Kenny et al., 1998, p. 239). Accordingly, we computed the means for the three persons who had previously been in a given group (Problems 2, 3, and 4 for GIII, Problems 3 and 4 for GGII, Problem 4 for GGGI), giving 35 scores for the respective problems in these conditions. Since the 105 individuals in the IIII condition were completely independent of each other, we did not average over these 35 sets of three individuals.

Table 1 gives the mean trials to solution and standard deviations for the GGGG, GGGI, GGII, GIII, and IIII Conditions for Problems 1, 2, 3, and 4. A preliminary 5 (conditions: GGGG, GGGI, GGII, GIII, IIII) × 4 (problems: 1, 2, $3,4)$ analysis of variance for trials to solution indicated significant main effects of condition $(F(4,240)=10.75, p<.001, M S E=13.8068)$, and problems $(F(3,720)=80.99, p<.001$, $M S E=1.5409)$, and a significant Conditions $\times$ Problems interaction $(F(12,720)=4.88$, $p<.001)$.

Means for GGGG, GGGI, GGII, GIII, and IIII were $4.87,5.15,4.94,5.32$, and 6.62 , respectively. Tukey pairwise comparisons (at $p<.01$ ) indicated that each of GGGG, GGGI, GGII, and GIII had significantly fewer trials to solution than IIII and did not differ significantly from each other. This is consistent with Hypotheses 1, 2, 3, and 4, but of course, does not test them directly or completely. Means for Problems 1, 2, 3, and 4 were $6.76,5.64,5.38$, and 5.16, respectively. A significant linear trend indicated improvement over the four problems $(F(1,720)=$ $204.81, p<.001)$, and a significant quadratic trend indicated major improvement from Problem 1 to Problem 2 and progressively decreased improvement from Problems 2 to 3 to $4(F(1,720)=32.54, p<.001)$. Table 2 gives the results of the 16 contrasts directly testing Hypotheses 1, 2, 3, and 4. All contrasts were tested with the error term for the respective problem. 
Table 1. Means and standard deviations for trials to solution $(\mathrm{G}=$ Group, $\mathrm{I}=$ Individual $)$

\begin{tabular}{lcccccccc}
\hline Condition & \multicolumn{2}{c}{ Problem 1 } & \multicolumn{2}{c}{ Problem 2 } & \multicolumn{2}{c}{ Problem 3 } & \multicolumn{2}{c}{ Problem 4 } \\
\hline GGGG & 6.26 & $(2.05)$ & 4.74 & $(1.95)$ & 4.57 & $(1.61)$ & $3.91 \quad(0.95)$ \\
GGGI & 6.09 & $(2.61)$ & 4.86 & $(1.68)$ & 4.63 & $(1.54)$ & 5.03 & $(1.83)$ \\
GGII & 5.40 & $(2.13)$ & 4.38 & $(1.50)$ & 5.08 & $(1.83)$ & $4.90 \quad(1.72)$ \\
GIII & 5.86 & $(1.61)$ & 5.48 & $(1.99)$ & 4.95 & $(1.72)$ & $4.99(1.62)$ \\
IIII & 7.91 & $(2.69)$ & 6.67 & $(2.74)$ & 6.14 & $(2.79)$ & $5.75 \quad(2.40)$ \\
\hline
\end{tabular}

Table 2. Tests of four hypotheses for trials to solution ( $\mathrm{G}=$ Group, $\mathrm{I}=$ Individual, $\mathrm{SES}=$ standard effect size 1$)$

\begin{tabular}{|c|c|c|c|c|c|}
\hline Hypothesis & Problem & Contrast and means on trials to solution & $F(1,240)$ & $p<$ & SES \\
\hline \multirow[t]{4}{*}{$\mathrm{G}>\mathrm{I}$} & One & (\#1) (GGGG, GGGI, GGII, GIII) 5.90 vs. IIII 7.91 & 42.70 & .001 & .78 \\
\hline & Two & (\#3) (GGGG, GGGI, GGII) 4.66 vs. IIII 6.67 & 43.70 & .001 & .81 \\
\hline & Three & (\#8) (GGGG, GGGI) 4.60 vs. IIII 6.14 & 21.89 & .001 & .62 \\
\hline & Four & (\#12) GGGG 3.91 vs. IIII 5.75 & 26.81 & .001 & .90 \\
\hline \multirow[t]{6}{*}{ Transfer } & Two & (\#4) GIII 5.48 vs. IIII 6.67 & 7.67 & .01 & .76 \\
\hline & Three & (\#5) GIII 4.95 vs. IIII 6.14 & 8.13 & .01 & .47 \\
\hline & & (\#9) GGII 5.08 vs. IIII 6.14 & 6.54 & .01 & .42 \\
\hline & Four & (\#10) GGII 4.91 vs. IIII 5.75 & 5.69 & .05 & .38 \\
\hline & & (\#11) GIII 4.99 vs. IIII 5.75 & 4.61 & .05 & .35 \\
\hline & & (\#15) GGGI 5.03 vs. IIII 5.75 & 4.15 & .05 & .33 \\
\hline \multirow[t]{3}{*}{ Sufficient } & Three & (\#6) GGII 5.08 vs. GIII 4.95 & $<1$ & & \\
\hline & Four & (\#13) GGII 4.91 vs. GIII 4.99 & $<1$ & & \\
\hline & & (\#14) GGGI 5.03 vs. GIII 5.75 & $<1$ & & \\
\hline \multirow[t]{3}{*}{ Complete } & Two & (\#2) (GGGG, GGGI, GGII) 4.66 vs. GIII 5.48 & 3.63 & & \\
\hline & Three & (\#7) (GGGG, GGGI) 4.60 vs. (GGII, GIII) 5.01 & 1.32 & & \\
\hline & Four & (\#16) GGGG (3.91) vs. (GGGI, GGII, GIII) 4.97 & 8.93 & .01 & .83 \\
\hline
\end{tabular}

Note: Contrast numbers are based on Figure 1.

\section{Hypothesis 1. Groups will perform better than} individuals As indicated in Table 2, Contrast 1 testing group versus individual performance on Problem 1, Contrast 3 on Problem 2, Contrast 8 on Problem 3, and Contrast 12 on Problem 4 were all significant, supporting Hypothesis 1 and indicating that the groups performed better than the control individuals on each of Problems 1, 2, 3, and 4. This superiority of group over individual problem solving is a highly likely, if not necessary, prerequisite for positive group-to-individual transfer to occur, although some members could conceivably learn something during group problem solving even if the groups did not perform better than the individuals.
Hypothesis 2. Positive group-to-individual transfer will occur As indicated in Table 2, Contrast 4 testing for group-to-individual transfer on Problem 2, Contrasts 5 and 9 on Problem 3, and Contrasts 10, 11, and 15 on Problem 4 were all significant. This supports Hypothesis 2 and demonstrated consistent positive groupto-individual transfer: transfer individuals with varying previous group experience consistently performed better than control individuals without any previous group experience.

Hypothesis 3. One previous group experience is sufficient for positive group-to-individual transfer to occur As indicated in Table 2, Contrast 6 testing for sufficiency on Problem 3 
and Contrasts 13 and 14 testing for sufficiency on Problem 4 were nonsignificant: the GIII individuals who had previously solved one problem in a group performed as well on Problem 3 as the GGII individuals who had previously solved two problems in a group. Similarly, the GIII individuals who had solved only one problem as a group performed as well on Problem 4 as the GGII individuals who had previously solved two problems as a group and the GGGI individuals who had previously solved three problems as a group. These results confirm Hypothesis 3 and indicate that one previous group experience was sufficient for positive group-to-individual transfer to occur for the letters-to-numbers problems.

Hypothesis 4. Group-to-individual transfer will be complete As indicated in Table 2, the GIII individuals did not differ significantly from the GGGG, GGGI, and GGII groups on Problem 2 (Contrast 2). Similarly, the GGII and GIII individuals did not differ significantly from the GGGG and GGGI groups on Problem 3 (Contrast 7). This indicates that group-to-individual transfer on Problems 2 and 3 was complete, or at the level of group performance. However, the GGGI, GGII, and GIII individuals did not perform as well as the GGGG groups on Problem 4 (Contrast 16). This indicates that although positive group-to-individual transfer occurred on Problem 4, it was not up to the level of the GGGG controls who solved all four problems as a group. Thus, Hypothesis 4 was supported for Problems 2 and 3, but not for Problem 4.

In summary, (a) groups performed better than individuals, (b) positive group-to-individual transfer occurred, (c) one group experience was sufficient for positive group-to-individual transfer to occur, and (d) group-to-individual transfer was complete, or at the level of group performance, on Problems 2 and 3, but not on Problem 4.

\section{Types of expressions}

We first categorized each expression as ignored value, unknown value, or known value. An expression was considered ignored value if (a) there was no plus or minus sign (e.g. A, AB,
ABCDEFGHIJ), (b) the expression was too complex to be processed given the known letters at the time (e.g. ABCDE $-\mathrm{F}+\mathrm{G}+\mathrm{H}+\mathrm{I}+\mathrm{J}$ on Trial 1), or (c) the expression was repeated from a previous trial (e.g. A + B on Trial 2 and Trial 1). In unknown value expressions the problem solver does not know the value of the expression when the expression is proposed. In known value expressions the problem solver does know the value of the expression when it is proposed, and hence can identify letters in the expression from the value of the expression. For example, the expression $\mathrm{A}+\mathrm{B}+\mathrm{C}+\mathrm{D}+\mathrm{E}$ $+\mathrm{F}+\mathrm{G}+\mathrm{H}+\mathrm{I}+\mathrm{J}$ which adds all 10 letters has a known value of 45: if the value is $\mathrm{GC}, \mathrm{G}$ is 4 and C is 5 (see Laughlin et al., 2002, 2003 for further elaboration and illustrations of unknown value, known value, and mixed strategies). We then conducted multiple regressions of trials to solution on the proportions of ignored value, unknown value, and known value expressions for the group, transfer individual, or individual conditions on each problem.

On Problem 1 the multiple $R$ for groups (Conditions GGGG, GGGI, GGII, GIII), was .38 $(p<.001)$, with a significant positive slope for ignored value expressions $(p<.001)$, a significant negative slope for unknown value expressions $(p<.01)$, and a nonsignificant slope for known value expressions. The multiple $R$ for the IIII individuals was $.32(p<.001)$, with a significant positive slope for ignored value expressions $(p<.02)$, a significant negative slope for unknown value expressions $(p<.02)$, and a nonsignificant slope for known value expressions. Thus, for both groups and individuals the use of ignored value expressions related to poorer performance (more trials to solution), the use of unknown value expressions related to better performance, and the use of known value expressions had no effect.

On Problem 2 the multiple $R$ for groups (Conditions GGGG, GGGI, GGII) was .33 $(p<.01)$, with a significant positive slope for ignored value expressions $(p<.05)$, and nonsignificant slopes for unknown value expressions and known value expressions. The multiple $R$ for the GIII transfer individuals was nonsignificant. The multiple $R$ for the IIII individuals 
was $.40(p<.001)$, with a significant positive slope for ignored value expressions $(p<.001)$, a significant negative slope for unknown value expressions $(p<.001)$, and a nonsignificant slope for known value expressions. Thus, the use of ignored value expressions related negatively to performance for both groups and individuals, the use of unknown value expressions related positively to performance for individuals, and there were no relationships between the use of the three types of expressions for the GIII transfer individuals.

On Problem 3 the multiple $R$ for groups (Conditions GGGG, GGGI) was nonsignificant. The multiple $R$ for the transfer individuals (GGII, GIII) was .52 $(p<.001)$, but the slopes for ignored value, unknown value, and known value expressions were not significant. The multiple $R$ for the IIII individuals was .31 $(p<.02)$, but the slopes for ignored value $(p<.07)$ and unknown value $(p<.08)$ did not attain conventional levels of significance and the slope for known value expressions was nonsignificant.

On Problem 4 the multiple $R$ for the GGGG groups was nonsignificant. The multiple $R$ for the transfer individuals (Conditions GGGI, GGII, GII) was .33 $(p<.01)$, with a significant positive slope for ignored value expressions $(p<.01)$, a nonsignificant slope for unknown value expressions, and a significant negative slope $(p<.05)$, for known value expressions. Thus, there was evidence for positive group-to-transfer by avoiding ineffective ignored value expressions and using effective known value expressions. The multiple $R$ for the IIII individuals was .28 $(p<.05)$, with a positive slope for the use of ignored value expressions $(p<.01)$, a negative slope for the use of unknown value expressions $(p<.01)$, and a nonsignificant slope for the use of known value expressions.

In summary, the multiple regressions of trials on the proportions of ignored value, unknown value, and known value expressions were significant for the groups on Problems 1 and 2, the individuals on all four Problems, and the transfer individuals on Problem 4. The groups learned to avoid ignored value expressions, or guessing, after the first problem, but performance related to the use of ignored value expressions for the individuals on all four problems. Performance related to the proportion of known value expressions for the groups on Problem 1 and the individuals on Problems 1 and 2, but not thereafter. Although group performance did not relate to the use of effective known value expressions on Problems 1 , 2 , or 3 , there was evidence of group-to-individual transfer of these effective strategies for the transfer individuals on Problem 4.

\section{Discussion}

\section{Four issues of group-to-individual problem-solving transfer}

The results for the basic performance measure of trials to solution provide strong evidence on the four issues of positive group-to-individual problem-solving transfer. First, the groups performed better than the individuals, which is a basic requisite for positive group-to-individual transfer. Second, individuals with previous group experience consistently performed better than individuals without previous group experience, demonstrating positive group-to-individual transfer. Third, one group experience was sufficient for the group-to-individual transfer effect to occur, demonstrating sufficiency. That is, for this task, all the benefit that came from prior group experience was obtained through one's first such experience. Finally, transfer was at the level of group performance on Problems 2 and 3 , demonstrating the completeness of transfer, but was less than group performance on Problem 4, for which the group performance was exceptional. The latter effect suggests that some of the benefits of prior group experience may take a certain amount of time to fully emerge.

The multiple regression analyses of trials on the proportions of ignored value, unknown value, and known value expressions indicated that the groups learned to avoid ignored value expressions better than the individuals and there was evidence for transfer of effective known value expressions on Problem 4.

Before the experiment we conducted a computer simulation of a strategy of pure guessing (ignored value expressions) in which the simulated problem solver enters any expression, 
ignores the resulting value, and assigns a unique nonredundant number to each of the remaining unidentified letters on each trial. This simulation gave an expected value of 5.59 trials to solution, and Figure 4 presents a histogram. This allows another informative theoretical baseline. There was a mean of 5.90 trials over the four group conditions and a mean of 7.91 for the individuals on Problem 1, or poorer performance than the expected value from pure guessing. Although the IIII control individuals improved over problems, they did not improve to the level of pure guessing. In contrast, the groups and the individuals with previous group experience on average performed better than this expected value on each of Problems 2, 3, and 4 . In addition to assigning nonredundant numbers to unidentified letters within and across trials, as done in the simulation of a pure guessing or ignored value strategy, the members of the problem solving groups learned to propose informative expressions and reason effectively from the values of the expressions, and this transferred to their subsequent individual performance on new problems. Hence comparison of the performance of individuals who had been in groups with the expectations of a pure guessing strategy provides additional evidence of group-to-individual transfer.

These results extend the small research literature demonstrating specific group-to-individual transfer on verbal analogies problems (Laughlin \& Adamopoulos, 1980) and mathematical problems (Laughlin \& Ellis, 1986), and general group-to-individual transfer on mathematical problems (Stasson et al., 1991) and brainteaser problems (Olivera \& Straus, 2004). All four of these studies used only a single training session and single transfer session, and hence could address only the first and second issues of the four issues in group-to-individual transfer that we have considered here. The current experiment used one, two, three, or four group training problems, and hence was able to extend previous research to the interesting issues of the sufficiency of one group experience for transfer and the completeness of transfer relative to comparably experienced groups.

\section{Future research}

Group-to-individual transfer is an important but underresearched area (Kerr \& Tindale, 2004) and the current study suggests several issues for future research. Since sufficiency and completeness of

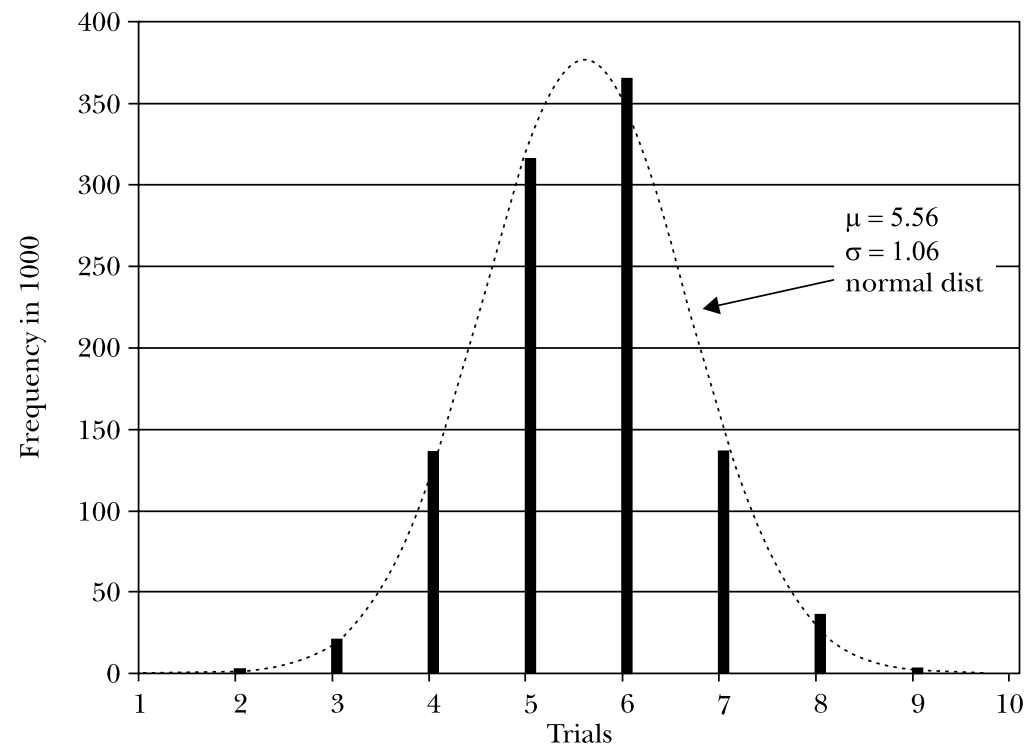

Figure 4. Histogram for simulation of pure guessing (ignored value) strategy. 
group-to-individual problem-solving transfer raise many important theoretical and practical issues, future research could usefully investigate more training and transfer problems than the single training session and single transfer session of most previous research. Although we believe that our experiment demonstrates the occurrence, sufficiency, and partial completeness of group-to-individual transfer on lettersto-numbers problems, these problems are an abstraction from the more complex problems faced by groups and individuals in scientific, educational, business, military, political, and other groups and teams. Thus, future research could test the generality of our current results for other classes of problems. Similarly, the members of our groups were of equal status, and future research could assess group-to-individual transfer in hierarchical groups of members with different functional responsibilities (e.g. Ellis et al., 2003; Hedlund, Ilgen, \& Hollenbeck, 1998; Ilgen, Hollenbeck, Johnson, \& Jundt, 2005).

As in all previous research on group-toindividual transfer we have assumed that our problem-solving groups engaged in cooperative interaction, where all group members share the same objective and share equally in the rewards or punishments of successful or unsuccessful group performance. Similarly, research on information sharing in the hidden profile paradigm (Stasser \& Titus, 1983) has assumed cooperative interaction. Wittenbaum, Hollingshead, and Botero (2004) have proposed that further research should proceed from cooperative to motivated information sharing in groups, realizing that group members have-in addition to a common shared objective of successful group performance-their own motives and interests, such as impressing others, winning arguments, unwillingness to elaborate the ideas of others, and so forth. In their classic study of mock juries Hastie, Penrod, and Pennington (1983) distinguished six types of motives of jury members beyond the basic objective of discovering the truth of the case and making the proper decision, such as advancing the interests of individuals at the trial (e.g. the defendant), groups outside the trial (e.g. defendants in general), or winning arguments. Beyond the directive leadership, premature consensus, feelings of moral superiority, and other causes and symptoms of groupthink (Janis, 1982), Halberstam (1969) demonstrates the strong motives of the Presidential Advisors in these fiascos to acquiesce in decisions they privately doubted in order to 'remain players'. These considerations suggest that future research on group-to-individual problem solving could usefully address such motivated information sharing in cooperative groups.

\section{Acknowledgments}

This research was supported in part by an NSF grant (BCS-0518316) to the third author. We thank Olivia Castellanos, Jana Curran, and David Harris for assistance in conducting the experiment.

\section{References}

Ellis, A. P. J., Hollenbeck, J. R., Ilgen, D. R., Porter, C. G. L. H., West, B. J., \& Moon, H. (2003). Team learning: Collectively connecting the dots. Journal of Applied Psychology, 88, 821-835.

Halberstam, D. (1969). The best and the brightest. New York: Random House.

Hastie, R., Penrod, S. D, \& Pennington, N. (1983). Inside the jury. Cambridge, MA: Harvard University Press.

Hedlund, J., Ilgen, D. R., \& Hollenbeck, J. R. (1998). Decision accuracy in computer-mediated versus face-to-face groups. Organizational Behavior and Human Decision Processes, 76, 30-47.

Ilgen, D. R., Hollenbeck, J. R., Johnson, M., \& Jundt, D. (2005). Teams in organizations: From input-process-output models to IMOI models. Annul Review of Psychology, 56, 517-543.

Janis, I. L. (1982). Groupthink: Psychological studies of policy decisions and fiascos (2nd ed.). Boston: Houghton-Mifflin.

Kenny, D. A., Kashy, D. A., \& Bolger, N. (1998). Data analysis in social psychology. In D. Gilbert, S. Fiske, \& G. Lindzey (Eds.), The handbook of social psychology (Vol. 1, 4th ed., pp. 233-265). Boston: McGraw-Hill.

Kenny, D. A., Mannetti, L., Pierro, A., Livi, S., \& Kashy, D. A. (2002). The statistical analysis of data from small groups. Journal of Personality and Social Psychology, 83, 126-137. 
Kerr, N. L., Stasser, G., \& Davis, J. H. (1979). Model-testing model-fitting, and social decision schemes. Organizational Behavior and Human Performance, 23, 399-410.

Kerr, N. L., \& Tindale, R. S. (2004). Group performance and decision making. Annual Review of Psychology, 45, 819-828.

Laughlin, P. R., \& Adamopoulos, J. A. (1980). Social combination processes and individual learning for six-person cooperative groups on an intellective task. Journal of Personality and Social Psychology, 38, 941-947.

Laughlin, P. R., Bonner, B. L, \& Miner, A. G. (2002). Groups perform better than the best individuals on letters-to-numbers problems. Organizational Behavior and Human Decision Processes, 88, 605-620.

Laughlin, P. R., \& Ellis, A. L. (1986). Demonstrability and social combination processes on mathematical intellective tasks. Journal of Experimental Social Psychology, 22, 177-189.

Laughlin, P. R., Hatch, E. C., Silver, J. S., \& Boh, L. (2006). Groups perform better than the best individuals on letters-to-numbers problems: Effects of group size. Journal of Personality and Social Psychology, 90, 644-651.

Laughlin, P. R., Zander, M. L., Knievel, E. M., \& Tan, T. K. (2003). Groups perform better than the best individuals on Letters-to-Numbers problems: Informative equations and effective reasoning. Journal of Personality and Social Psychology, 85, 684-694.

Olivera, F., \& Straus, S. G. (2004). Group-toindividual transfer of learning. Small Group Research, 35, 440-465.

Stasser, G., \& Titus, W. (1983). Pooling of unshared information in group decision making: Biased information sampling during discussion. Journal of Personality and Social Psychology, 48, 1467-1468.
Stasson, M. F., Kameda, T., Parks, C. D., Zimmerman, S. K., \& Davis, J. H. (1991). Effects of assigned group consensus requirements on group problem solving and group members' learning. Social Psychology Quarterly, 54, 25-35.

Wittenbaum, G. M., Hollingshead, A. B., \& Botero, I. C. (2004). From cooperative to motivated information sharing in groups: Moving beyond the hidden profile paradigm. Communication Monographs, 71, 286-310.

Paper received 16 August 2007; revised version accepted 19 November 2007.

\section{Biographical notes}

PATRICK R. LAUGHLIN received his PhD from Northwestern University in 1964 . He is currently professor of psychology (emeritus) at the University of Illinois at Urbana-Champaign. His research interests include group learning, problem solving, and decision making.

HAROLD R. CAREY received his BS in physics and maths from Benedictine University in 1959. He is currently a consultant for COLSA Corporation, Huntsville, Alabama. His research interests include the structure, management, and processes of multidisciplinary project teams.

NORBERT L. KERR received his $\mathrm{PhD}$ from the University of Illinois at Urbana-Champaign, in 1974. He is currently professor of psychology at Michigan State University. His research interests include group performance, group decision making, social dilemmas, social exclusion, and psychology and the law. 